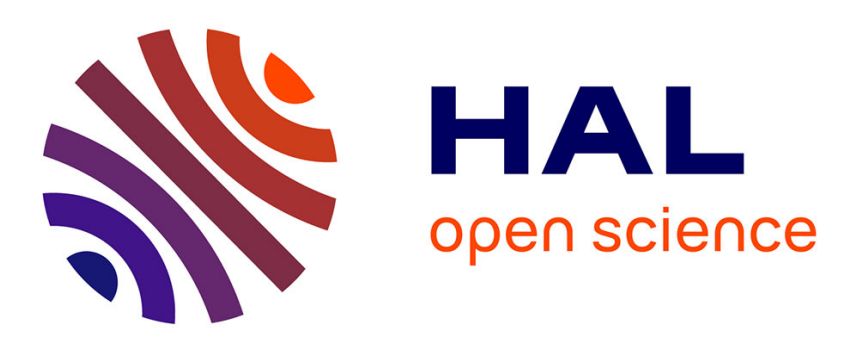

\title{
3-phenylpropionate catabolism and the Escherichia coli oxidative stress response
}

Evelyne Turlin, Odile Sismeiro, Jean Pierre Le Caer, Valérie Labas, Antoine Danchin, Francis Biville

\section{- To cite this version:}

Evelyne Turlin, Odile Sismeiro, Jean Pierre Le Caer, Valérie Labas, Antoine Danchin, et al.. 3phenylpropionate catabolism and the Escherichia coli oxidative stress response. Research in Microbiology, 2005, 156 (3), pp.312 - 321. 10.1016/j.resmic.2004.10.012 . hal-01636923

\section{HAL Id: hal-01636923 https://hal.science/hal-01636923}

Submitted on 20 Nov 2017

HAL is a multi-disciplinary open access archive for the deposit and dissemination of scientific research documents, whether they are published or not. The documents may come from teaching and research institutions in France or abroad, or from public or private research centers.
L'archive ouverte pluridisciplinaire HAL, est destinée au dépôt et à la diffusion de documents scientifiques de niveau recherche, publiés ou non, émanant des établissements d'enseignement et de recherche français ou étrangers, des laboratoires publics ou privés. 


\title{
3-phenylpropionate catabolism and the Escherichia coli oxidative stress response
}

\author{
Evelyne Turlin ${ }^{a}$, Odile Sismeiro ${ }^{\mathrm{b}}$, Jean Pierre Le Caer ${ }^{\mathrm{c}}$, Valérie Labas ${ }^{\mathrm{c}}$, Antoine Danchin ${ }^{\mathrm{a}}$, \\ Francis Biville ${ }^{\mathrm{d}, *}$ \\ a Unité de Génétique des Génomes Bactériens, Département de Structure et dynamique des génomes, Institut Pasteur, 28 rue du Dr. Roux, \\ 75724 Paris cedex 15, France \\ ${ }^{\mathrm{b}}$ Plate-Forme 2-Puces à ADN, Département de Structure et dynamique des génomes, Institut Pasteur, 28 rue du Dr. Roux, 75724 Paris cedex 15, France \\ ${ }^{\mathrm{c}}$ Neurobiologie et Diversité Cellulaire, CNRS UMR 7637, Ecole Supérieure de Physique et Chimie Industrielles de la Ville de Paris, 10 rue Vauquelin, \\ 75005 Paris, France \\ d Unité de Génétique des Membranes Bactériennes, Département de Microbiologie Fondamentale et Médicale, Institut Pasteur, 25 rue du Dr. Roux, \\ 75724 Paris cedex 15, France
}

Received 1 July 2004; accepted 19 October 2004

Available online 8 December 2004

\begin{abstract}
Cells have devised a variety of protection systems against the toxic effects of dioxygen. Dioxygenases are part of this defence mechanism. In Escherichia coli, the positive regulator HcaR, a member of the LysR family of regulators, controls expression of the neighbouring genes, $h c a A 1, h c a A 2, h c a C, h c a B$ and $h c a D$, coding for the 3-phenylpropionate dioxygenase complex and 3-phenylpropionate-2', $3^{\prime}$-dihydrodiol dehydrogenase, that oxidizes 3-phenylpropionate to 3-(2,3-dihydroxyphenyl) propionate. Differences between expression of $h c a R$ and expression of its target, $h c a A$, suggest that HcaR is involved in control of other cellular processes or that other regulatory proteins modulate $h c a A$ expression. Protein expression profiling was used to identify other HcaR targets. Two-dimensional gel electrophoresis was used to compare the proteomes of wild-type $E$. coli and strains in which $h c a R$ was disrupted. Several polypeptides whose production was up- or downregulated in the $h c a R$ mutant were involved in the oxidative stress response. Subsequent experiments demonstrated that $h c a R$ disruption was involved in regulation of genes involved in the oxidative stress response. Modification of the stress response also occurred in an hca $A 1 A 2 C D$ mutant strain. Using gel retardation, the HcaR binding site was estimated to be located about -70 to -55 bp upstream of the $h c a A$ transcription start site. The expression of $h c a R$ was repressed in the absence of oxygen by the ArcA/ArcB two-component system. (C) 2004 Elsevier SAS. All rights reserved.
\end{abstract}

Keywords: Oxidative stress; LysR; Proteome comparison; ArcA/ArcB

\section{Introduction}

Despite its many roles in electron transfer reactions providing energy to the cell, dioxygen is a very toxic compound, generating numerous kinds of reduced forms of oxygen species (RFO) [32]. Dioxygenases, that directly scavenge dioxygen, may therefore play an important role in protecting the cell against the deleterious effects of oxygen.

\footnotetext{
* Corresponding author.

E-mail address: fbiville@ pasteur.fr (F. Biville).
}

In Escherichia coli, HcaA is a dioxygenase which affects the metabolism of 3-phenyl propionic acid. HcaR, a member of the LysR family of regulatory proteins [34], was initially identified as a positive regulator of the hcaA 1 , $A 2, C, B$ and $D$ operon [6]. Its disruption abolishes growth on 3-phenyl propionic acid [6,38]. The production of HcaR, the hcaR gene product, increases during stationary phase in an rpoS-independent manner [38] and is also subject to glucose-dependent repression [38]. A comparative study of regulation of the first step in 3-phenylpropionate catabolism and regulation of $h c a R$ revealed that HcaR may play a pleiotropic role [38]. Sequence compar- 
isons with bacterial polypeptides contained in databases (http://www.genome.wisc.edu/, http://www.ncbi.nlm.nih. gov/, and http://www.genomesonline.org/) revealed that HcaR authentic homologs are present only in some enterobacteria, such as E. coli $\mathrm{O} 157: \mathrm{H} 7$, Shigella flexneri, and Photorhabdus luminescens (http://genolist.pasteur.fr/ PhotoList/). The presence of $h c a R$ may be related to the specific biotope encountered by these bacterial species. This conjecture prompted us to try and identify other putative targets of HcaR. In this report, using 2D gel electrophoresis to analyse the $E$. coli proteome, we showed that the disruption of $h c a R$ up- or downregulated the production of 30 proteins involved in various processes, 22 of which were identified. We subsequently showed that the absence of HcaR generates significant changes in control of the stress response. The relationship between $h c a R$ expression levels and the presence of oxygen was also investigated.

\section{Materials and methods}

\subsection{Bacterial strains, plasmids and growth conditions}

The bacterial strains and plasmids used in this study are listed in Table 1. Bacteria were cultivated aerobically at $37^{\circ} \mathrm{C}$ in LB medium or minimal media M63 [16] supplemented with gluconate $(0.4 \%)$ or succinate $(0.2 \%)$ as carbon sources. When specified, sodium nitrite $\mathrm{NaNO}_{3}$ was added at a final concentration of $40 \mathrm{mM}$. Anaerobic cultures were grown in Erlenmeyer flasks with rubber stoppers and with shaking. Anoxia was achieved by bubbling with $\mathrm{N}_{2}$ for

Table 1

Stains, plasmids, and phages used in this study

\begin{tabular}{|c|c|c|}
\hline Strains & Relevant characteristics & Source or reference \\
\hline BL21 DE3 & $\begin{array}{l}\text { gal omp } T \text { lysogen of DE3 } \\
\text { carrying } \mathrm{T} 7 \text { polymerase gene }\end{array}$ & [35] \\
\hline FB8 & $\mathrm{F}^{-}$ & [3] \\
\hline FB85 & $\mathrm{F}^{-}$, hcaR::cat & [38] \\
\hline FB80 & $\mathrm{F}^{-}, \Delta l a c$ X74 & [21] \\
\hline FB82 & $\mathrm{F}^{-}$, Llac X74, hcaR::lacZ & [38] \\
\hline FB825 & $\begin{array}{l}\mathrm{F}^{-}, \text {Dlac X74, hcaR::lacZ, } \\
\text { oxyR::Kan }\end{array}$ & This study \\
\hline FB826 & $\begin{array}{l}\mathrm{F}^{-}, \Delta \text { lac X74, hcaR::lacZ, } \\
\text { soxR::cat }\end{array}$ & This study \\
\hline FB827 & $\begin{array}{l}\mathrm{F}^{-}, \text {Dlac X74, hcaR::lacZ, } \\
\text { arcA::Kan }\end{array}$ & This study \\
\hline $\mathrm{FB} 82 \Delta 1$ & $\mathrm{~F}^{-}$, Llac X74, hcaR $\Delta 1:: l a c Z$ & This study \\
\hline $\mathrm{FB} 82 \Delta 2$ & $\mathrm{~F}^{-}, \Delta l a c$ X74, hcaR $\Delta 2:: l a c Z$ & This study \\
\hline \multicolumn{3}{|l|}{ Plasmids } \\
\hline pRS415 & $\mathrm{Ap}^{\mathrm{R}}$ & {$[30]$} \\
\hline pET22b & $\mathrm{Ap}^{\mathrm{R}}$ & Novagen cat. no. $69744-3$ \\
\hline PDIA10120 & $\begin{array}{l}\text { 4.6-kb fragment of } E \text {. coli } \\
\text { inserted into pUC18 (c37.11) }\end{array}$ & {$[38]$} \\
\hline pDIA10122 & hcaR inserted into pET22b & This study \\
\hline \multicolumn{3}{|l|}{ Phage } \\
\hline$\lambda \operatorname{RS} 45$ & & [30] \\
\hline
\end{tabular}

2 min. Antibiotics were added to the following final concentrations $(\mu \mathrm{g} / \mathrm{ml})$ as required: chloramphenicol $(\mathrm{Cm}), 20$; kanamycin (Km), 25; ampicillin (Amp) 50. Solid media contained $1.5 \%$ Difco agar.

\subsection{Genetic techniques}

P1 lysates and transductions were done as described by Miller [16]. Cells were transformed by the calcium chloride method [14] or electroporation [7].

\subsection{Construction of chromosomal operon fusions}

The 304-bp EcoRI-BamHI and 258-bp EcoRI-BamHI DNA fragments, containing the $\Delta 1$ and $\Delta 2$ promoter regions of hcaR (Fig. 2), were amplified using pDIA 10120 as template, with $5^{\prime}$-AAGCCGACCGTCGAATTCACCACG-3' and 5' -ATCGCGGATCCGCGCCGTAGTTCCATCACC- $3^{\prime}$, or with $5^{\prime}$-CCGAATTCCAAATCTGAGGGTGTGGTC-3' and $5^{\prime}$-AAGATCGCGGATCCGGCTGC-3' as primers. After restriction cutting and gel separation, these fragments were purified and inserted into the multiple cloning site of pRS415, in front of the lac operon, and transferred by homologous recombination into $\lambda \mathrm{RS} 45$. This phage was then used to lysogenise the FB80 strain as previously described [30] thus giving strains FB82 $\Delta 1$, and FB82 $\Delta 2$. Single lambda prophage integration was confirmed by PCR [22].

\subsection{DNA manipulations and molecular cloning}

Chromosomal DNA was isolated according to the Marmur method [15]. Large-scale plasmid DNA preparations were carried out using the Plasmid Maxi kit (Qiagen Inc., Germany) as recommended by the manufacturer. Smallscale plasmid DNA preparations were done as described by Birnboim and Doly [1]. Restriction, modification and ligation were carried out according to the manufacturer's recommendations. After gel separation, DNA fragments of interest were isolated by use of the QIAquick gel extraction kit (Qiagen Inc., Germany). DNA fragments were amplified in a Hybaid PCR thermocycler, using the Expand High Fidelity PCR system (Boerhinger, Germany).

\subsection{Primer extension}

Total RNA was isolated from E. coli FB8 grown in minimal medium supplemented with $0.2 \%$ succinate. Exponentially growing cells were harvested at an $\mathrm{OD}_{600 \mathrm{~nm}}$ of 0.8 and collected by centrifugation. Total RNA was extracted by use of the High Pure RNA Isolation kit from Roche. The primers, R1 (5'-TAGTTCCATCACCTTCCCCTTGTTATCG- $3^{\prime}$ ) and A1 (5'-AATCAGTTGGTAAATGTTCAAATCTGAGGGTGTGG-3') (see Fig. 2 for positions of the primers), were labelled with $\alpha\left[{ }^{-32} \mathrm{P}\right]$-ATP and hybridised with $10 \mu \mathrm{g}$ of RNA. The same primers were used to generate 
Table 2

Sequences of the PCR primers

\begin{tabular}{|c|c|c|}
\hline Gene & Forward & Reverse \\
\hline $\operatorname{sod} A$ & 5'-TATGCTTACGATGCCCTGGAACCGCACTTCG-3' & 5'-AATGTAGTCCGGACGGCGGTTCTGGAATTTA-3' \\
\hline $\operatorname{sod} B$ & 5'-ATGCTCTGGCACCGCACATTTCTGC-3' & 5'-TTCACCAGCGCCCAGAAGTGCTCC-3' \\
\hline $\operatorname{sod} C$ & 5'-TAGTCTGGCTATTCTGGCGCTGG-3' & 5'-TTCACCGCCACCGCCCAGCGGTTTAGG-3' \\
\hline katE & 5'-AACTCACTGCGTGCCGGTAGCCGTGG-3' & 5'-TAGCGGCTATAGGCAACACCGTACCG-3' \\
\hline$k a t G$ & 5'-ATCTCAACCGTGGTGGCCAGCCG-3' & 5'-AAGTTGGCACCCAGTACACGCATGCC-3' \\
\hline $\operatorname{ahpC}$ & 5'-ATACCGAAGGCCGCTGGAGCG-3' & 5'-ATTGCCTGGATGATACCCTGCG-3' \\
\hline$a h p F$ & 5'-TACCTTGAGAAATTGACCAAGCC- $3^{\prime}$ & 5'-TACGTTCGACTGCGCCTTCGAGCC-3’ \\
\hline$m r s A$ & 5'-ATGCCCTGCCTGGACGTAACACC-3' & 5'-TTCCGCCAATTCCACAGTAACCATACG-3' \\
\hline gor & 5'-TATCGCCTCCATCAACCGCGCGGC-3' & 5'-ATGCGGCACGGCTGGCGGTGAGTGG-3’ \\
\hline $\operatorname{tr} x B$ & 5'-AACACAGTAAACTGCTTATCCTGGG- $3^{\prime}$ & 5'-AAGTGCTGCCATGCAGCCTGTACCG-3' \\
\hline
\end{tabular}

a sequence ladder using the Sanger method [26]. Annealing was performed at $80^{\circ} \mathrm{C}$. Elongation of the DNA primer using reverse transcriptase and analysis of the products was performed as described previously [25].

\subsection{Slot blot analyses}

Digoxigenin-labelled probes were obtained by use of the PCR DIG probe synthesis kit from Roche. The primers used are listed in Table 2. Total RNA was extracted from exponentially growing cells by the High Pure RNA Isolation kit from Roche. Increasing amounts $(50,100,200$, and $400 \mathrm{ng})$ of total RNA were transferred to a positively charged nylon membrane and hybridised with the DIG-labelled probes. Chemiluminescent detection was performed with anti-DIG$\mathrm{AP}$ and CDP-Star (Roche). The chemiluminescent signal was detected on X-ray film after 1-5 min exposure time. The slot blots were analysed and quantified by Image Master 1D software from Pharmacia.

\subsection{Gel shift assay}

Gel shift assays were performed according to methods described by Parsek et al. [20]. An end-labelled 274-bp fragment was generated by standard PCR using the ${ }^{33} \mathrm{P}-$ primers hcaR8 ( $5^{\prime}$-AAG ATC GCG GAT CCG GCT GC- $3^{\prime}$ ) and hcaR31 ( $5^{\prime}$-CCG AAT TCC AAA TCT GAG GGT GTG GTC-3'). Different amounts of purified HcaR protein were incubated with a fixed low DNA concentration $(5000 \mathrm{cpm}$ corresponding to $1-5 \mathrm{fmol}$ of the labelled DNA fragment) in $10 \mu \mathrm{l}$ of incubation buffer $\left(\mathrm{KCl} 50 \mathrm{mM}, \mathrm{MgCl}_{2} 10 \mathrm{mM}\right.$, glycerol $10 \%$, Tris- $\mathrm{HCl} 50 \mathrm{mM}$, pH 7.9, Nonidet P-40 $0.1 \%$ ) containing $50 \mathrm{ng} / \mathrm{ml}$ poly dIdC and $0.3 \mathrm{mg} / \mathrm{ml}$ bovine serum albumin. After $30 \mathrm{~min}$ at room temperature, bromphenol blue-glycerol loading dye as added and the samples were immediately loaded onto a vertical non-denaturing 5\% polyacrylamide gel and separated at $+4{ }^{\circ} \mathrm{C}$ in TBE buffer ( $89 \mathrm{mM}$ Tris, $89 \mathrm{mM}$ boric acid, $2 \mathrm{mM}$ EDTA; $\mathrm{pH}$ 8.2) at $12 \mathrm{~V} / \mathrm{cm}$. The dried gel was exposed to PhosphorImager scanning.

\subsection{Production of HcaR}

To overproduce and to purify HcaR protein, the hcaR gene was amplified by PCR using (5'-AAT TCC ATA TGG AAC TAC GGC ATT TAC GC-3') and (5'-CCC CTC GAG CGG TGC CGT TAC GCT TGC CAA ACG-3') as forward and reverse primers. The PCR product was digested with NdeI and XhoI and then cloned into the pET22b expression vector under control of the inducible T7lac promoter (Novagen cat. no. 69744-3) yielding pDIA10122. A 1.5-1 culture of E. coli BL21 (DE3) [35] containing pDIA10122 was grown aerobically at $30^{\circ} \mathrm{C}$ in LB medium supplemented with Ap $(100 \mu \mathrm{g} / \mathrm{ml})$ and $\mathrm{Cm}(20 \mu \mathrm{g} / \mathrm{ml})$. When the $\mathrm{OD}_{600 \mathrm{~nm}}$ reached 2, IPTG $(0.5 \mathrm{mM})$ was added to the medium to induce hcaR expression. One hour after induction, bacteria were harvested by centrifugation. The pellet was resuspended in $75 \mathrm{ml}$ of buffer $\mathrm{A}(\mathrm{NaCl} 300 \mathrm{mM}$, $\mathrm{NaH}_{2} \mathrm{PO}_{4} 50 \mathrm{mM}$, imidazole $20 \mathrm{mM}, \mathrm{pH}$ 8). Lysozyme was added at a final concentration of $1.5 \mathrm{mg} / \mathrm{ml}$ and the mixture was incubated for $30 \mathrm{~min}$ at $4{ }^{\circ} \mathrm{C}$. The cells were disrupted by sonication and the bacterial extract was centrifuged at $12000 \mathrm{~g}$ for $30 \mathrm{~min}$ at $4{ }^{\circ} \mathrm{C}$. The supernatant was centrifuged again in the same conditions and kept for further purification.

\subsection{Purification of HcaR in native conditions}

The purification procedure was adapted from the QIAexpress Protein Purification system from Qiagen (http://www. qiagen.com). All steps were performed at $+4^{\circ} \mathrm{C}$. The supernatant $(75 \mathrm{ml})$, obtained as above, was mixed with $4 \mathrm{ml}$ of Ni-NTA superflow resin (Qiagen, cat. no. 30410) and packed in a $5 \mathrm{ml}$ polypropylene column (Qiagen, cat. no. 34964) by gravity flow. After two washes with $8 \mathrm{ml}$ buffer A, the protein was recovered by elution with increasing concentrations of imidazole (100, 200 and $300 \mathrm{mM}$ ) in buffer A. The fractions with the best purification profiles on SDS-PAGE gel were applied to a PD-10 column Sephadex G-25M (Pharmacia Biotech, cat. 17-0851-01) and eluted directly with one volume of buffer $\mathrm{B}\left(\mathrm{NaCl} 500 \mathrm{mM}, \mathrm{NaH}_{2} \mathrm{PO}_{4} 40 \mathrm{mM}\right.$, $\mathrm{pH}$ 8). The fractions obtained at each step were analysed by SDS-PAGE. Most of the HcaR protein was recovered in the 100 and $200 \mathrm{mM}$ imidazole fractions. The purified protein does not support freezing but was stable at $+4{ }^{\circ} \mathrm{C}$ in buffer 
B complemented with sodium azide $0.01 \%$ for a few weeks. The protein was estimated to be ca. $95 \%$ pure on SDS-PAGE gel.

\subsection{Analytical 2D gel electrophoresis}

Strains FB8 and FB85 were grown in minimal medium with succinate. Exponentially growing cells $(100 \mathrm{ml}$ of $\mathrm{OD}_{600 \mathrm{~nm}}=0.4$ ) were harvested by centrifugation. The pellet was then resuspended in $1 \mathrm{ml}$ of distilled water and $15 \mu \mathrm{l}$ of a DNase $(1 \mathrm{mg} / \mathrm{ml}) /$ RNase $(0.5 \mathrm{mg} / \mathrm{ml})$ solution was added. Cells were disrupted at $4{ }^{\circ} \mathrm{C}$ by a Branson sonifier $250(3 \times 20 \mathrm{~s})$ and the cell debris was removed by ultracentrifugation $\left(60 \mathrm{~min}, 4^{\circ} \mathrm{C}, 90000 \mathrm{~g}\right)$. Approximately $100 \mu \mathrm{g}$ of proteins were resuspended in sample buffer (Pharmalyte 3-10 0.5\%, urea $8 \mathrm{M}$, DTT $100 \mathrm{mM}$, Nonidet P40 2\%) (ratio 1/5). Immobiline DryStrips ( $\mathrm{pH} \mathrm{4-7)} \mathrm{and} \mathrm{the} \mathrm{Mul-}$ tiphor II Isoelectric system from Pharmacia were used for isoelectric focusing. Strips were rehydrated for $16 \mathrm{~h}$ at $20^{\circ} \mathrm{C}$ and then focused for $45000 \mathrm{~V} \mathrm{~h}^{-1}$. The second dimension was performed with $11.5 \%$ polyacrylamide gels in the presence of SDS, using the Protean II 2D Multi-Cell system from BioRad. The gels were then fixed in $40 \%$ ethanol/10\% acetic acid and silver-stained. The gels were digitised by a JX-330 scanner (Sharp, Hamburg, Germany). Spot detection and quantification were performed on a SPARC station $5 \mathrm{mi}-$ crocomputer (Sun Microsystem, Mountain View, CA) using the PDQUEST software package (BioRad, Ivry, France).

\subsection{MALDI-TOF spectrometry}

Protein spots were excised and the gel slices were digested with trypsin (Roche) as described previously [29]. The matrix used for the desalted digestions was a saturated solution of 2,5-dihydroxybenzoic acid (DHB) in TFA $0.1 \%$. MALDI-TOF spectra were obtained with a VoyagerDE STR Biospectrometry Workstation mass spectrometer (PE Biosystems Inc., Framingham, MA). The analysis was performed in positive ion reflector mode. The trypsin autoproteolysis products were used as internal standards. Data mining was performed by the ProFound and MS-FIT software against non-redundant databases. A mass deviation of 0.1-0.3 Da was allowed in the database searches.

\subsection{Protein determination}

Protein concentrations were determined as described by Bradford [2] using bovine serum albumin as the standard.

\subsection{Enzyme assays}

$\beta$-Galactosidase was assayed by the method described by Pardee et al. [19]. The activities of HPI and HPII catalases were measured as described previously [39].

\section{Results}

\subsection{Proteome modifications generated by disruption of the hcaR gene}

To identify putative targets of HcaR, we studied the proteome modifications generated by the disruption of its structural gene $h c a R$. In a first set of experiments, strains FB8 and its hcaR::cat derivative (FB85) were grown in M63 minimal medium with succinate as the carbon source (hcaR is highly expressed in bacteria grown with this carbon source [38]). After cell disruption, proteins were separated on a 2D SDS-PAGE gel, silver-stained, scanned and matched with a reference gel as described in Section 2. The amount of 51 polypeptides was affected by hcaR inactivation. The amount of 25 polypeptides increased and that of 26 polypeptides decreased. The comparison of spots of interest with our database, which contained 170 identified polypeptides from E. coli, combined with mass spectrometry, enabled 22 of these to be identified (Table 3). Three proteins (enolase, fructose-biphosphate aldolase and triosephosphate isomerase), the expression of which was decreased in the hcaR mutant, were involved in glycolysis. In contrast, the amount of phosphoenolpyruvate synthase, involved in gluconeogenesis, increased twofold in the mutant and may have compensated for the decrease in the three glycolysis enzymes for phosphoenolpyruvate biosynthesis. The amount of two tricarboxylic acid cycle enzymes (aconitate hydratase 2 and malate dehydrogenase) also decreased in the $h c a R$ mutant. In contrast, the expression level of the $\beta$ chain of ATP synthase was strongly increased in the mutant and may have compensated for the decrease in the two enzymes of the TCA cycle. Disruption of $h c a R$ decreased the expression level of proteins involved in S-adenosylmethionine (AdoMet) metabolism (methionine adenosyltransferase). This might consequently modify the level of polyamine synthesis. This was not the case, however, because the amount of the different polyamines synthesized in the hcaR mutant did not vary when compared to the wild type (data not shown). The increase in PotD, a membrane protein involved in the transport of spermidine from the periplasm to the cytoplasm [10], could compensate for the decrease in spermidine that is formed from decarboxylated AdoMet and putrescine.

Several observations prompted us to explore the effect of hcaR disruption on the expression level of genes involved in the oxidative stress response: (i) the amount of thioredoxin reductase increased (this enzyme reduces thioredoxin used by the cell to reduce the disulphur bonds generated by protein oxidation) [37]; (ii) the amount of the stress response protein, DnaK, which accumulates in E. coli after exposure to hydrogen peroxide [17], increased; (iii) the amount of Mn-dependent superoxide dismutase (MnSOD) [36] decreased in the hcaR mutant. 
Table 3

Identification of polypeptides up or downregulated in the hcaR mutant FB85. Bacteria were grown in M63 minimal medium with succinate as carbon source

\begin{tabular}{|c|c|c|c|c|}
\hline Gene & Protein & $\begin{array}{l}\text { Swissprot } \\
\text { accession } \\
\text { number }\end{array}$ & FB85/FB8 & Metabolic process \\
\hline eno & Enolase & P08324 & $\mathrm{R} / 2$ & Glycolysis \\
\hline$f b a A$ & Fructose-biphosphate aldolase & P11604 & $\mathrm{R} / 2$ & Glycolysis \\
\hline tpiA & Triosephosphate isomerase & P04790 & $\mathrm{R} / 2$ & Glycolysis \\
\hline $\operatorname{glp} K$ & Glycerol kinase & P08859 & $\mathrm{R} / 2$ & Glycerol catabolism \\
\hline aceF & Pyruvate dehydrogenase & P06959 & $\mathrm{R} / 2$ & Pyruvate dehydrogenase \\
\hline $\operatorname{acn} B$ & Aconitate hydratase 2 & P36683 & $\mathrm{R} / 5$ & Tricarboxylic acid cycle \\
\hline$m d h$ & Malate dehydrogenase & P06994 & $\mathrm{R} / 3$ & Tricarboxylic acid cycle \\
\hline ppsA & PEP synthase & P23538 & $\mathrm{I} \times 2$ & Gluconeogenesis \\
\hline atpB & ATP synthase beta chain & P00824 & $I \times 4$ & ATP synthesis \\
\hline $\operatorname{trp} A$ & Tryptophan synthase subunit A & P00928 & $\mathrm{R} / 2$ & Tryptophan biosynthesis \\
\hline$g d h A$ & Glutamate dehydrogenase & P00370 & $\mathrm{R} / 2$ & Glutamate biosynthesis \\
\hline $\operatorname{argS}$ & Arginyl-tRNA synthetase & P11875 & $\mathrm{R} / 2$ & tRNA charging pathway \\
\hline $\operatorname{ser} S$ & Seryl-tRNA synthetase & P09156 & $\mathrm{R} / 2$ & tRNA charging pathway \\
\hline metK & Methionine adenosyltransferase & P04384 & $\mathrm{R} / 5$ & S-adenosyl-L-methionine synthesis \\
\hline potD & Subunit of putrescine/spermidine $\mathrm{ABC}$ transporter & $\mathrm{P} 23861$ & $\mathrm{I} \times 4$ & Polyamine transport \\
\hline upp & Uracil phosphoribosyltransferase & P25532 & $\mathrm{R} / 4$ & Pyrimidine ribonucleotides salvage pathway \\
\hline purA & Adenylosuccinate synthetase & P12283 & $\mathrm{R} / 5$ & Purine nucleotide biosynthesis \\
\hline $\operatorname{sod} A$ & Superoxidedismutase (Mn) & P00448 & $\mathrm{R} / 2$ & Oxidative stress \\
\hline $\operatorname{trx} B$ & Thioredoxin reductase & P09625 & $\mathrm{I} \times 2$ & Thioredoxin pathway \\
\hline dnaK & HSP-70-type molecular chaperone & P04475 & $I \times 4$ & Stress response \\
\hline $\operatorname{rps} A$ & Ribosomal protein S1 & P02349 & $\mathrm{R} / 2$ & Translation \\
\hline pnp & Polyribonucleotide nucleotidyltransferase & P05055 & $\mathrm{R} / 2$ & RNA degradation \\
\hline
\end{tabular}

Exponentially growing cells $\left(100 \mathrm{ml}\right.$ of $\left.\mathrm{OD}_{600 \mathrm{~nm}}=0.4\right)$ were harvested by centrifugation. After $2 \mathrm{D}$ electrophoresis, spot quantification induction (I) and repression $(\mathrm{R})$ factors were calculated as described in Section 2.

\subsection{Effects of hcaR disruption on expression of genes involved in the oxidative stress response}

The oxidative stress response involves mechanisms that lower the intracellular concentration of oxygen and its reduced forms (RFO) and repair damage generated by the interaction of these compounds with DNA, amino acids, proteins and phospholipids. We found that HcaR controls the production of two proteins involved respectively in the enzymatic interception of RFO (MnSOD) and in repair of their toxic activity for proteins (thioredoxin reductase). To determine whether HcaR also modulates production levels of other proteins involved in control of RFO and their effects, slot blot experiments were performed with RNA extracted from strains FB8 and FB85 harvested either during the exponential or during the stationary growth phase. The probes used in these slot blot experiments were derived from genes involved in control of RFO and/or their effects. Disruption of hcaR modified the expression levels of genes involved in interception of RFO (Table 4). The expression levels of all three genes encoding superoxide dismutases (involved in the dismutation of superoxide ions) $\operatorname{sod} A$, $\operatorname{sodB}$, and $\operatorname{sod} C$ decreased both during the exponential growth and during the stationary phase in an hcaR mutant. The expression level of the katG and katE genes, encoding respectively the two distinct catalases HPI and HPII involved in hydrogen peroxide dismutation [8], was the same in the wild-type strain and in its $h c a R$ derivative during the exponential growth phase. In contrast, during the stationary phase, the expres-
Table 4

Effect of hcaR disruption on expression levels of genes involved in the oxidative stress response

\begin{tabular}{lll}
\hline Gene & Exponential growth & Stationary phase \\
\hline $\operatorname{sod} A$ & $/ 1.2$ & $/ 1.5$ \\
$\operatorname{sod} B$ & $/ 1.3$ & $/ 1.8$ \\
$\operatorname{sod} C$ & $/ 1.6$ & $/ 2.1$ \\
KatE & $=$ & $=$ \\
katG & $=$ & $/ 2$ \\
ahpC & $=$ & $/ 2$ \\
ahpF & $=$ & $/ 5$ \\
gor & $/ 3$ & $/ 3$ \\
msrA & $\times 3.2$ & $=$ \\
trxB & $\times 1.6$ & $=$ \\
\hline
\end{tabular}

Bacteria were grown in M63 minimal medium with succinate as carbon source. Samples were harvested during exponential growth or stationary phase and RNA were extracted and hybridised to the probes as described in Section 2.

sion of kat $G$ was significantly decreased in the hcaR mutant (Table 4). HPI and HPII catalase activities were assayed in crude extracts of FB8 and FB85 strains harvested during the stationary phase. HPI activity was sevenfold lower in the hcaR mutant (Table 5). Disruption of hcaR decreased expression of $a h p C$ and $a h p F$ which encode the two subunits of alkyl hydroperoxide reductase which functions as a primary scavenger of endogenous $\mathrm{H}_{2} \mathrm{O}_{2}$ [28]. The expression level of genes involved in repair of damage generated by the interaction of RFO compounds with amino acids and proteins was also altered by $h c a R$ disruption. Indeed, the expression level of gor, coding for glutathione reductase that reduces 
Table 5

Effect of $h c a R$ inactivation on HPI $(k a t G)$ and HPII $(k a t F)$ catalase activities

\begin{tabular}{llc}
\hline & FB8 & FB85 \\
\hline HPI + HPII & $55 \pm 6$ & $24 \pm 2$ \\
HP II & $27 \pm 3$ & $20 \pm 1$ \\
HP I & $28 \pm 4$ & $4 \pm 0.5$ \\
\hline
\end{tabular}

Bacteria were grown in M63 minimal medium with succinate as carbon source. Catalase activities in extracts of FB8 and FB85 grown to stationary phase were measured by the spectrometric method as cited in Section 2.

oxidized glutathione and reduces the disulphur bonds generated by protein oxidation [11], was threefold lower in the $h c a R$ mutant during both the exponential growth phase and the stationary phase (Table 4). In contrast, the expression level of $\operatorname{tr} x B$, the structural gene of thioredoxin reductase which participates in various redox reactions through reversible oxidation of the thioredoxin-active dithiol centre to a disulphide, was increased by disruption of hcaR during exponential growth (Table 4). The dithiol-disulphide exchange reaction reduces the disulphur bonds generated by protein oxidation [24]. Also, the expression level of $m s r A$, encoding the methionine sulphoxide reductase that catalyses the reduction to methionine of methionine sulphoxide present in proteins [24], was increased threefold in the hcaR mutant only during exponential growth (Table 4).

\subsection{Effects of hcaA disruption on expression of the genes involved in the oxidative stress response}

The effect of HcaR disruption on the expression level of genes involved in the oxidative stress response may be direct or indirect. An indirect effect could be the consequence of the strong decrease in $h c a A 1, A 2, C, B, D$ operon expression in the absence of HcaR [38]. The effect of $h c a A 1$, $A 2, C, B, D$ operon disruption upon the expression level of genes involved in the oxidative cell response was investigated. Disruption of the $h c a A 1, A 2, C, B, D$ operon also significantly decreased $k a t G$ (twofold), sodA (threefold), and $\operatorname{sod} C$ (sixfold) expression during the stationary growth phase. Thus, the effect of hcaR disruption on genes involved in the oxidative stress response was related to the decrease in expression of genes coding for enzymes implicated in the early steps of 3-phenyl propionic acid utilisation.

\subsection{The expression level of $\mathrm{hcaR}$ is related to aerobic metabolism}

As shown above, the function of $h c a R$ is related to the oxidative stress response during the exponential and stationary phases. We thus searched for a relationship between the $h c a R$ expression level and oxidative metabolism. In a first set of experiments, expression of $h c a R$ was measured in bacteria grown anaerobically or aerobically in the presence or absence of compounds known to induce oxidative stress responses. hcaR::lacz transcriptional fusion was not induced after incubation with sublethal doses of $\mathrm{H}_{2} \mathrm{O}_{2}$, paraquat or
Table 6

Expression of the hcaR::lacZ transcriptional fusion for bacteria grown in the absence or in the presence of oxygen

$\beta$-galactosidase specific activity

(nmoles substrate converted/min mg dry weight bacteria)

$\mathrm{M} 63 \mathrm{~B} 1+\mathrm{gln}+\mathrm{O}_{2} \mathrm{M} 63 \mathrm{~B} 1+\mathrm{gln}-\mathrm{O}_{2} \mathrm{M} 63 \mathrm{~B} 1+\mathrm{gln}-\mathrm{O}_{2}+\mathrm{NaNO}_{3}$ $200 \pm 6 \quad 45 \pm 1.5 \quad 45 \pm 1.5$

Bacteria were grown aerobically or anaerobically in M63 minimal medium with gluconate as carbon source in the absence or in the presence of sodium nitrite $\mathrm{NaNO}_{3}(40 \mathrm{mM})$ as an electron acceptor. For each experiment, $\beta$-galactosidase activity was assayed four or five times during exponential growth. The $\beta$-galactosidase specific activities are the average of at least three experiments; the error range represents one standard deviation.

cumene hydrogen peroxide (data not shown), known to induce superoxide dismutase [36], catalase [39] and cumene hydrogen peroxidase [33]. When bacteria were grown in the absence of oxygen, the expression of $h c a R$ was decreased threefold compared to growth in aerobic conditions (Table 6). This decrease was not alleviated by adding nitrate, which can serve as an electron acceptor and consequently allow the respiratory chain to work in the absence of oxygen (Table 6). Thus, the expression level of hcaR is either related to the presence of the dioxygen molecule or to some other feature of aerobic metabolism. The restoration of the full expression level of $h c a R$ required about two generations following the addition of oxygen during the mid-growth exponential phase in bacteria previously grown under anaerobic conditions (data not shown).

\subsection{Study of the intergenic region between hcaA and hcaR}

In order to gain insight into regulatory features that might be involved in this regulation we analysed the hcaR hcaA intergenic region. HcaR positively regulates the expression of its neighbouring genes, hcaA1, A2, $C, B, D$, and negatively regulates the expression of its own gene [38]. As a consequence, one or two HcaR binding sites could be present in the intergenic region between $h c a A$ and hcaR. The two mRNA $5^{\prime}$ ends of $h c a A$ and $h c a R$ were mapped using primer extension experiments as described in Section 2 (Fig. 1). A poor -10 region (AAGGAT) and a good -35 region (TTGACC) were found upstream of the transcription start site of $h c a R$ (Fig. 1). For $h c a A$, a weak -10 region (CAACAT) and a more typical -35 region (TTCACA) were found upstream of its transcription start site (Fig. 1). Generally, the DNA sites for LysR binding are located 35-80 bases upstream of the transcription start site of the target gene [27]. They are always extremely difficult to identify and no clear-cut consensus binding sites have been proposed for the LysR family of regulators [27]. We used three hcaR::lacZ transcriptional fusions to attempt to locate the DNA binding site for negative autoregulation of $h c a R$. The deletion of 153 bases from 237 to 86 bases upstream of the hcaR transcription start site increased its expression threefold (Fig. 2) (that is, to a level similar to that measured in a strain disrupted 


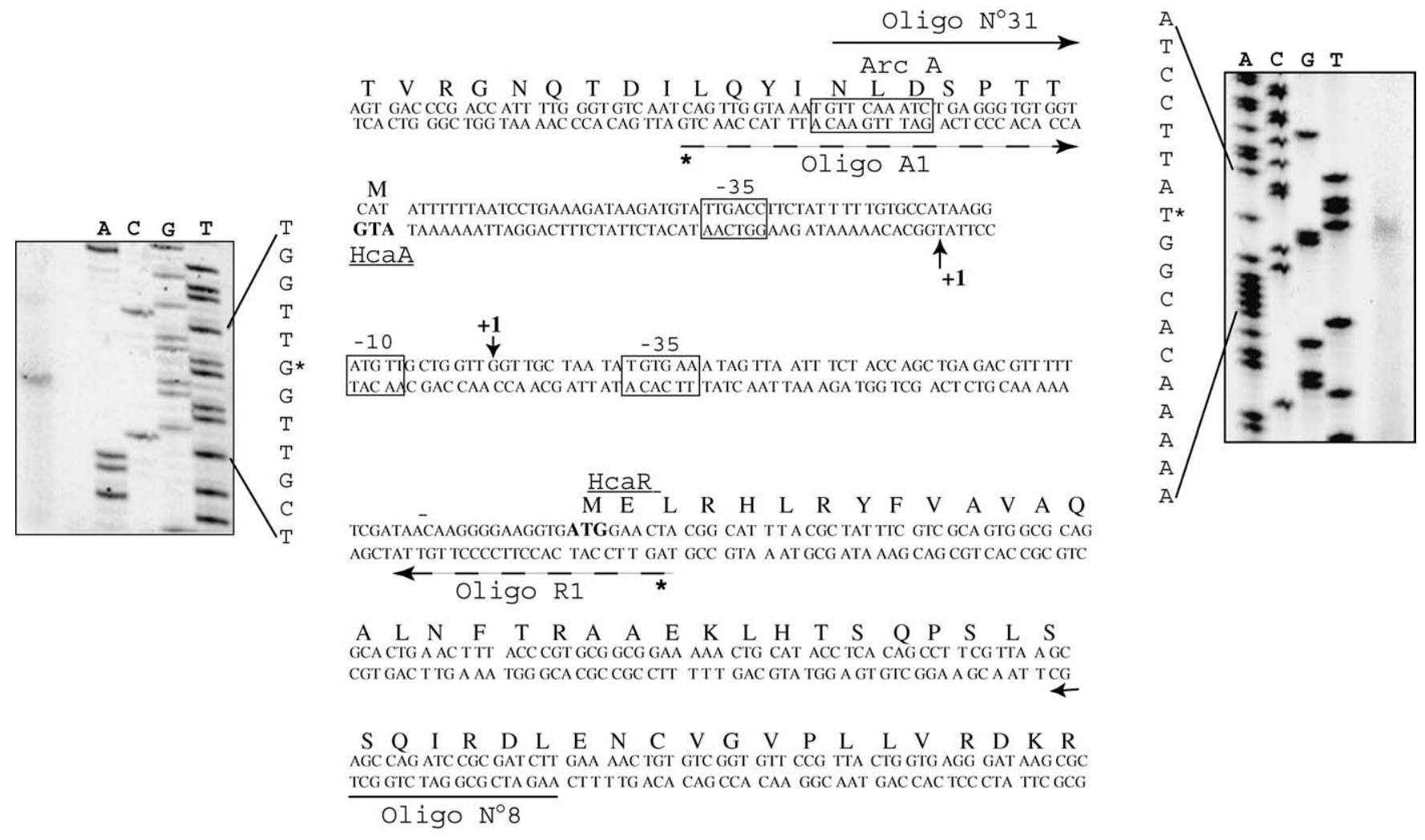

Fig. 1. The intergenic region between $h c a R$ and the $h c a A 1, A 2, C, B, D$ operon. Vertical arrows indicate the transcription start sites $(+1)$. The -35 and -10 regions and the proposed ArcA binding site are boxed. Sequences of primers used to amplify the fragment tested for gel retardation experiments (oligo 31 and oligo 8) are indicated by plain arrows. Mapping of the transcription starts at $h c a R$ and the $h c a A 1, A 2, C, B, D$ operon. Total RNA was extracted from E. coli strain FB8 grown in minimal medium in the presence of succinate. Primer extension experiments were performed using A1 oligonucleotide R1 (dashed arrow), for $h c a R$ and B oligonucleotide A1 (dashed arrow) for $h c a A$. Sequencing reactions (lane ACGT) were performed with the (R1) or (A1) oligonucleotides and pDIA 10120 as template. An asterisk indicates the $5^{\prime}$ end of mRNA.

\section{$\beta$-galactosidase specific activity nmole substrate converted/min.mg dry weight bacteria}

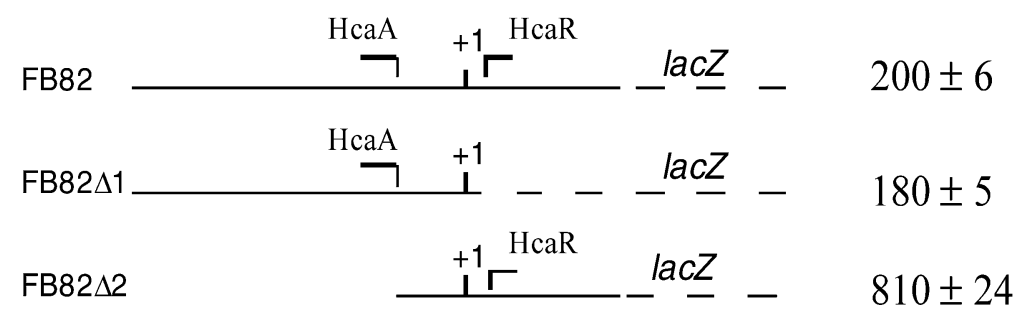

Fig. 2. Localization of the region required for negative autoregulation of $h c a R$. Bacteria were grown aerobically or anaerobically in M63 minimal medium with gluconate as carbon source. For each experiment, $\beta$-galactosidase activity was assayed four or five times during exponential growth. The $\beta$-galactosidase specific activities are the average of at least three experiments; the error range represents one standard deviation.

for hcaR [38]). In contrast, deletion of 107 bases from 67 to 172 bases downstream from the hcaR transcription start site had no effect on its negative autoregulation. Furthermore, we found that this 274-base fragment containing both $h c a A$ and $h c a R$ promoters was required for the induction of $h c a A$ in the presence of 3-phenylpropionate (data not shown).

To demonstrate that HcaR binds this DNA fragment, gel shift assays were performed with the pure HcaR protein isolated as described in Section 2. Addition of various amounts $(0.1-50 \mu \mathrm{g})$ of purified HcaR to the 274-bp fragment resulted in the formation of a DNA-protein complex with a mobility of 0.65 as compared to that of free DNA (Fig. 3). The complex was well detected with $0.5 \mu \mathrm{M}$ of HcaR. However, the addition of 3-phenylpropionate, which, when added to the growth medium, is the inducer of HcaR for the induction of $h c a A$, did not enhance formation of the DNA-protein complex (data not shown). The use of DNase1 protection experiments did not enable us to identify the bases involved in binding of HcaR to DNA. This may be due to the weak stability of the complex. 
Table 7

Expression of the $h c a R:$ lac $Z$ transcriptional fusion in a wild-type strain (FB82) and its oxyR (FB825), soxR (FB826), and $\operatorname{arcA}$ (FB827) derivatives

\begin{tabular}{lcrrr}
\hline & \multicolumn{3}{l}{$\begin{array}{l}\beta \text {-galactosidase specific activity } \\
\text { (nmoles substrate converted/min mg dry weight } \\
\text { bacteria) }\end{array}$} \\
& Control & \multicolumn{1}{c}{ oxyR } & \multicolumn{1}{c}{ soxR } & arc A \\
\hline M63 B1 + gln + O2 & $200 \pm 6$ & $230 \pm 7$ & $250 \pm 7.5$ & $350 \pm 10$ \\
M63 B1 + gln - O2 & $45 \pm 1.5$ & $50 \pm 1.5$ & $40 \pm 1.2$ & $400 \pm 12$ \\
\hline
\end{tabular}

Bacteria were grown aerobically or anaerobically in M63 minimal medium with gluconate as carbon source. For each experiment, $\beta$-galactosidase activity was assayed four or five times during exponential growth. $\beta$-Galactosidase specific activities are the average of at least three experiments; the error range represents one standard deviation.

\subsection{Expression of hcaR is regulated by the two-component system $\operatorname{arcA} / \operatorname{arcB}$}

Activators often act in concert with other regulators. It was therefore of interest to see whether we could find, upstream of hcaR, the signature of known regulators involved in monitoring the presence of oxygen. A putative ArcA binding site (TGTTCAAATC) was found 79 base pairs upstream of the hcaR transcription start site. This sequence matched 6 of the 10 bases of the consensus ArcA sequence (5' [A/T]GTTAATTA[A/T]) [12]. This prompted us to explore whether the $\mathrm{ArcA} / \mathrm{ArcB}$ two-component system was involved in regulation of $h c a R$ expression. The expression level of $h c a R$ was also measured in soxR and $o x y R$ mutants because SoxR [5] and OxyR [31] regulators modulate expression of many genes including sodA, gor, katG, ahpC and $a h p F$. Disruption of soxR or oxyR had no effect on hcaR expression (Table 7). This result is consistent with the fact that the addition of paraquat or hydrogen peroxide did not induce expression of hcaR. In contrast, disruption of $\operatorname{arcA}$ abolished the decrease in $h c a R$ expression when bacteria were grown in the absence of oxygen. Thus, hcaR can be considered a target of the ArcA/ArcB two-component system, but not of SoxR or OxyR. Nevertheless, this regulatory effect of the ArcA/ArcB two-component system seemed to be indirect, since deletion of the four proximal bases (TGTT) of the putative ArcA binding site had no effect on hcaR repression under anaerobic growth conditions (Fig. 4).

\section{Discussion}

Proteome comparison of an hcaR disruptant with its wild-type parent uncovered an unexpected relationship between HcaR activity and expression of genes involved in the oxidative stress response. The involvement of oxidative stress was further substantiated by slot blot hybridisation experiments using ten genes involved in the oxidative stress response as probes. The effect of hcaR inactivation on the oxidative stress response was shown to be related to its regulatory effects on hcaA. This effect occurs independently from $\operatorname{rpoS}$ that is normally expressed in hcaR

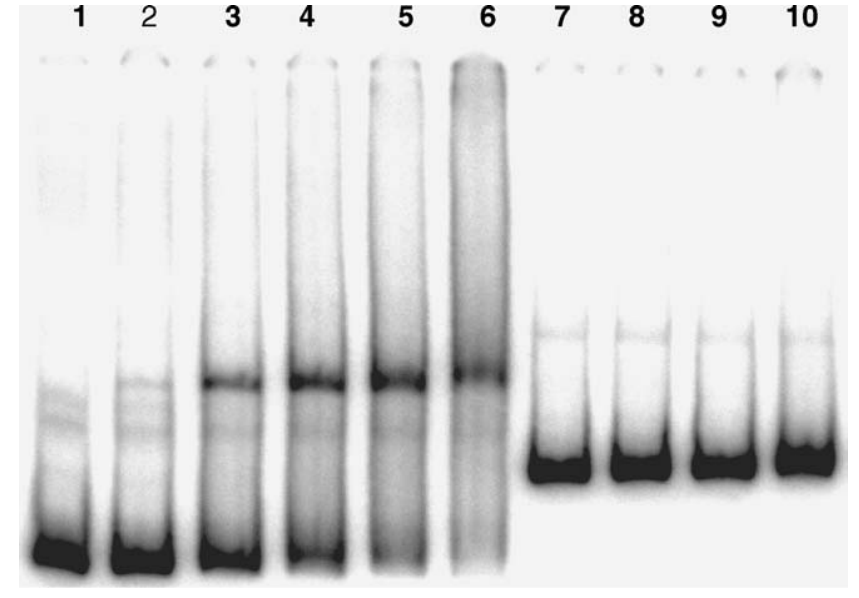

Fig. 3. Gel shift assay. Labelled DNA (1-5 fmol) was incubated with various amounts of purified $\mathrm{HcaR}$ for $30 \mathrm{~min}$ at room temperature and separated in a 5\% polyacrylamide gel as described in Section 2. A 274-bp fragment containing the $h c a A$ and $h c a R$ promoter regions was used in lanes 1-6; a 335-bp fragment that does not contain the hcaA and hcaR promoter regions was used in lanes 7-10 as a control for non-specific binding. Final protein concentrations were: lanes 1 and 7: no protein; lane 2: $0.1 \mu \mathrm{M}$; lanes 3 and 8: $0.5 \mu \mathrm{M}$; lanes 4 and 9: $1 \mu \mathrm{M}$; lanes 6 and 10: $5 \mu \mathrm{M}$.

and hacA disruptants (data not shown). The catalytic activity of the $h c a A$ gene product could be related to oxidative stress if we consider that one $\mathrm{O}_{2}$ molecule is incorporated into the 3-phenylpropionate molecule during its oxidation into cis-3-(carboxyethyl)-3,5-cyclohexadiene-1,2-diol by the 3-phenylpropionate dioxygenase system. The absence of this catalytic activity for $E$. coli strains grown with succinate as carbon source decreased the expression level of members of the OxyR regulon ( $a h p C, a h p F$, gor, katG) [41] and the SoxR-regulated gene ( $\operatorname{sodA})[13]$. Thus, impairment of 3-phenylpropionate dioxygenase activity could decrease production of reduced forms of oxygen species that were shown to induce $o x y R$ and $\operatorname{sox} R$ regulons, without any effect on the ability to survive oxidative stress generated by paraquat or $\mathrm{H}_{2} \mathrm{O}_{2}$ (data not shown). This absence of effects on oxidative stress responses can be explained by a concomitant increase in the expression level of genes like $m s r A$ [18] or $\operatorname{trx} B$ [23] that were shown to be involved in the repair of damage related to oxidative stress. Expression of HcaR was repressed in the absence of oxygen and our results imply that this regulation is the consequence of anaerobic metabolism. This is consistent with results showing that repression of hcaR in the absence of oxygen is due to the ArcA/ArcB two-component system [12], known to sense the redox state of the cell by detecting an electron transport component in its reduced form [9]. Our results also suggest that ArcA/ArcB-mediated control of hcaR expression is indirect. Thus, other regulatory events could interfere with ArcA control of hcaR expression that was shown to increase at the end of exponential growth [38]. The decrease in or absence of non-induced expression of the hcaA, A2, C, B, D operon modifies the number of polypeptides involved in oxidative catabolism and the stress response. This shows that, 
$\beta$-galactosidase specific activity

( nmoles substrate converted/min.mg dry weight bacteria)

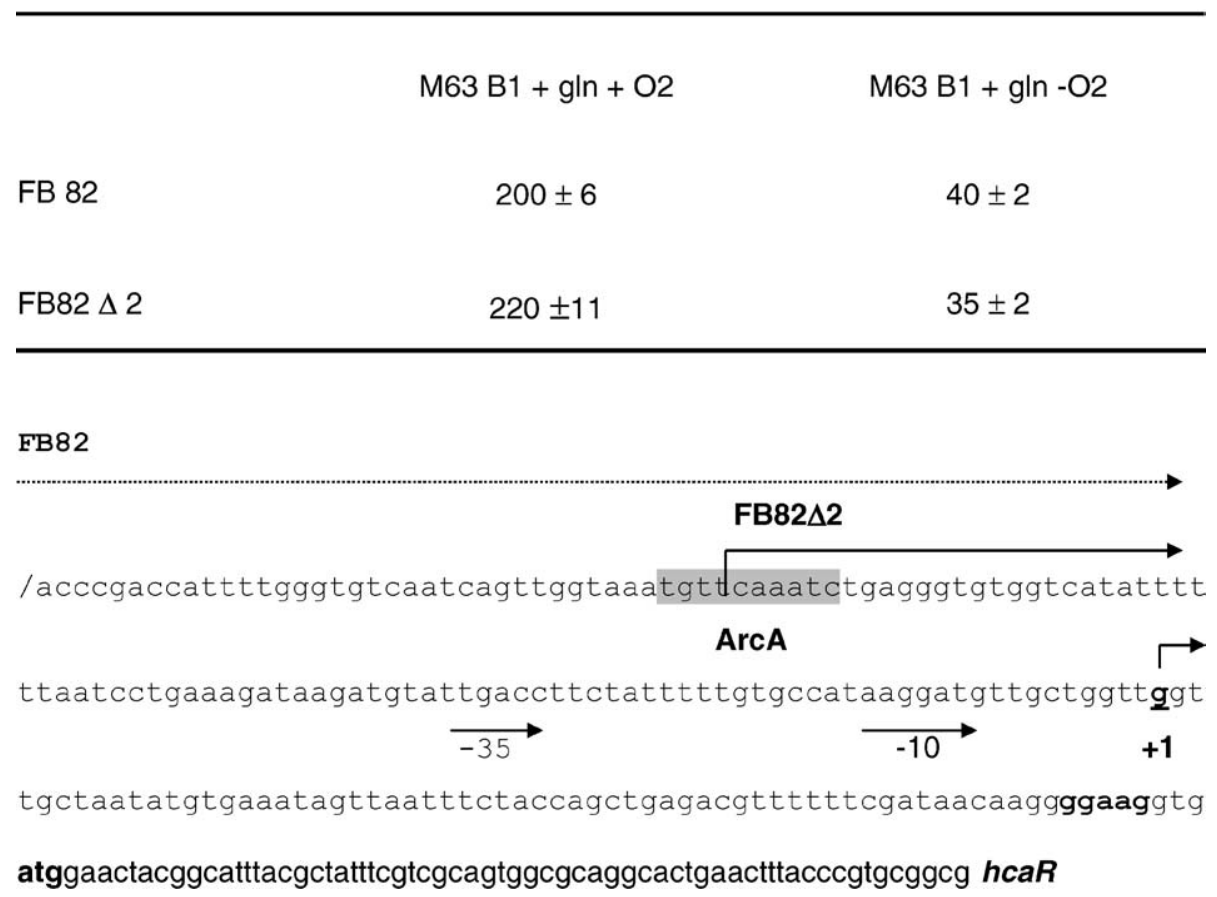

Fig. 4. Expression of hcaR::lacZ transcriptional fusion in a strain (FB82) and its derivative (FB82 $\Delta 2$ ) deleted for the four proximal bases of the putative ArcA binding site located upstream of hcar. Bacteria were grown aerobically or anaerobically in M63 minimal medium with gluconate as carbon source. For each experiment, the $\beta$-galactosidase activity was assayed four or five times during exponential growth. The $\beta$-galactosidase specific activities are the average of at least three experiments; the error range represents one standard deviation.

even in the absence of its cognate substrate, 3-phenyl propionic acid dioxygenase activity can play a role in modulation of the $E$. coli cell response to oxidative stress, mainly during the stationary phase. The presence of an active 3-phenyl propionic acid dioxygenase in a wild-type strains leads induction of members of $o x y R$ and sox $R$ regulons as compared with the hcaR and hcaA derivatives. Induction of such proteins enhances the bacterial cell response to oxidative stress. Expression of the $h c a A, A 2, C, B, D$ operon is not affected by $\operatorname{soxR}$ or $\operatorname{oxy} R$ disruption (data not shown) and thus cannot be considered as a target of OxyR or SorR.

Sequence comparison with polypeptides contained in databases of the partial or complete bacterial genome sequences (http://www.genomesonline.org/) only identified an HcaR homolog in pathogenic E. coli like O157:H7 (100\% identical) and Shigella flexneri (100\% identical). Among six pathogenic E. coli strains tested, only O157:H7 and the enterotoxinogen strain EDL 1493 were able to use 3-phenylpropionate as a carbon source (unpublished data). Also, HcaR was found in the Photorhabdus luminescens genome (47\% identical) (http://genolist.pasteur.fr/PhotoList/index. html). This suggests that the presence of HcaR is related to environments specifically encountered by some $E$. coli strains and $P$. luminescens. E. coli strains are present in human and animal intestines. $P$. luminescens is present in the gut of nematodes [40]. In human and animal intestines and in the gut of nematodes, 3-phenylpropionate is formed by the action of the microflora on plant constituents, tyrosine and phenylalanine [4]. The presence of the 3 -phenylpropionate catabolic pathway may be advantageous in these environments for defence against oxidative stress. Bacterial cells have evolved mechanisms that allow them to grow in favourable conditions and to survive in unfavourable conditions. In E. coli, groups of genes are involved in specific cell responses to heat, osmotic, and oxidative stress. In most of these cases, bacteria encounter less favourable environments than under the usual laboratory growth conditions. Consequently, a significant number of unknown genes, identified by complete genome sequencing programs, may be involved in responses to unfavourable environments. These cellular responses to unfavourable environments involve proteins specifically involved in stress responses and some enzymes and regulators of catabolic or anabolic pathways.

\section{Acknowledgements}

We wish to thank Danièle Touati, Klaus Hantke and Gisela Storz for generous gifts of strains. We wish to thank Sabrina Martin for technical help. Financial support came from the Pasteur Institute and the Centre de la Recherche Scientifique (URA 2171). 


\section{References}

[1] H.C. Birnboim, J. Doly, A rapid alkaline extraction procedure for screening recombinant plasmid DNA, Nucl. Acids Res. 7 (1979) $1513-1523$.

[2] M.M. Bradford, A rapid and sensitive method for the quantitation of microgram quantities of protein utilizing the principle of protein-dye binding, Anal. Biochem. 72 (1976) 248-254.

[3] C.B. Bruni, V. Colantuani, L. Sbordone, R. Cortese, F. Blasi, Biochemical and regulatory properties of Escherichia coli K-12 his T mutants, J. Bacteriol. 130 (1977) 4-10.

[4] R. Burlingame, P.J. Chapman, Catabolism of phenylpropionic acid and its 3-hydroxy derivative by Escherichia coli, J. Bacteriol. 155 (1983) 113-121.

[5] B. Demple, Redox signaling and gene control in the Escherichia coli soxRS oxidative stress regulon-a review, Gene 179 (1996) 53-57.

[6] E. Diaz, A. Ferrandez, J.L. Garcia, Characterization of the hca cluster encoding the dioxygenolytic pathway for initial catabolism of 3-phenylpropionic acid in Escherichia coli K-12, J. Bacteriol. 180 (1998) 2915-2923.

[7] W.J. Dower, J.F. Miller, C.W. Radgale, High efficiency transformation of $E$. coli by high voltage electroporation, Nucleic Acids Res. 16 (1988) 6127-6145.

[8] I. Fridovich, Superoxide radical: An endogenous toxicant, Annu. Rev. Pharmacol. Toxicol. 23 (1983) 239-257.

[9] D. Georgellis, O. Kwon, E.C. Lin, Quinones as the redox signal for the arc two-component system of bacteria, Science 292 (2001) 2314 2316.

[10] K. Igarashi, K. Ito, K. Kashiwagi, Polyamine uptake systems in Escherichia coli, Res. Microbiol. 152 (2001) 271-278.

[11] K.J. Kunert, C.F. Cresswell, A. Schmidt, P.M. Mullineaux, C.H. Foyer, Variations in the activity of glutathione reductase and the cellular glutathione content in relation to sensitivity to methylviologen in Escherichia coli, Arch. Biochem. Biophys. 282 (1990) 233-238.

[12] A.S. Lynch, E.C. Lin, Transcriptional control mediated by the ArcA two-component response regulator protein of Escherichia coli: Characterization of DNA binding at target promoters, J. Bacteriol. 178 (1996) 6238-6249.

[13] M. Manchado, C. Michan, C. Pueyo, Hydrogen peroxide activates the SoxRS regulon in vivo, J. Bacteriol. 182 (2000) 6842-6844.

[14] T. Maniatis, E.F. Fritch, J. Sanbrook, Molecular Cloning: A Laboratory Manual, Cold Spring Harbor Laboratory Press, Cold Spring Harbor, NY, 1989.

[15] J. Marmur, A procedure for the isolation of deoxyribonucleic acid from microorganisms, J. Mol. Biol. 3 (1961) 208-218.

[16] J.H. Miller, Experiments in molecular genetics, Cold Spring Harbor Laboratory Press, Cold Spring Harbor, NY, 1972.

[17] R.W. Morgan, M.F. Christman, F.S. Jacobson, G. Storz, B.N. Ames, Hydrogen peroxide-inducible proteins in Salmonella typhimurium overlap with heat shock and other stress proteins, Proc. Natl. Acad. Sci. USA 83 (1986) 8059-8063.

[18] J. Moskovitz, M.A. Rahman, J. Strassman, S.O. Yancey, S.R. Kushner, N. Brot, H. Weissbach, Escherichia coli peptide methionine sulphoxide reductase gene: Regulation of expression and role in protecting against oxidative damage, J. Bacteriol. 177 (1995) 502-507.

[19] A.B. Pardee, F. Jacob, J. Monod, The genetic control and cytoplasmic of inducibility in the synthesis of ß-galactosidase of Escherichia coli, J. Mol. Biol. 1 (1959) 165-178.

[20] M.R. Parsek, W.M. Coco, A.M. Chakrabarty, Gel-shift assay and DNase I footprinting in analysis of transcriptional regulation of biodegradative genes, Methods Mol. Genet. 3 (1994) 273-290.

[21] M. Perrotte-Piquemal, A. Danchin, F. Biville, Pyrophosphate increases the efficiency of enterobactin-dependent iron uptake in Escherichia coli, Biochimie 81 (1999) 245-253.
[22] B.S. Powell, M.P. Rivas, D.L. Court, Y. Nakamura, M.P. Rivas, C.L.J. Turnbough, Rapid confirmation of single copy lambda prophage integration by PCR, Nucleic Acids Res. 22 (1994) 5765-5766.

[23] M.J. Prieto-Alamo, J. Jurado, R. Gallardo-Madueno, F. Monje-Casas, A. Holmgren, C. Pueyo, Transcriptional regulation of glutaredoxin and thioredoxin pathways and related enzymes in response to oxidative stress, J. Biol. Chem. 275 (2000) 13398-13405.

[24] W.A. Prinz, F. Aslund, A. Holmgren, J. Beckwith, The role of the thioredoxin and glutaredoxin pathways in reducing protein disulphide bonds in the Escherichia coli cytoplasm, J. Biol. Chem. 272 (1997) 15661-15667.

[25] J. Sambrook, E.F. Fritsch, T. Maniatis, Molecular Cloning: A Laboratory Manual, second ed., Cold Spring Harbor Laboratory Press, Cold Spring Harbor, NY, 1989.

[26] F. Sanger, S. Nicklen, A.R. Coulson, DNA sequencing with chain termination inhibitors, Proc. Natl. Acad. Sci. USA 74 (1977) 5463-5467.

[27] M.A. Schell, Molecular biology of the LysR family of transcriptional regulators, Annu. Rev. Microbiol. 47 (1993) 597-626.

[28] L.C. Seaver, J.A. Imlay, Alkyl hydroperoxide reductase is the primary scavenger of endogenous hydrogen peroxide in Escherichia coli, J. Bacteriol. 183 (2001) 7173-7181.

[29] A. Shevchenko, M. Wilm, O. Vorm, M. Mann, Mass spectrometric sequencing of proteins silver-stained polyacrylamide gels, Anal. Chem. 68 (1996) 850-858.

[30] R.W. Simons, F. Houman, N. Kleckner, Improved single and multicopy lac-based cloning vectors for protein and operon fusions, Gene 53 (1987) 85-96.

[31] G. Storz, S. Altuvia, OxyR regulon, Methods Enzymol. 234 (1994) 217-223.

[32] G. Storz, J.A. Imlay, Oxidative stress, Curr. Opin. Microbiol. 2 (1999) 188-194.

[33] G. Storz, F.S. Jacobson, L.A. Tartaglia, R.W. Morgan, L.A. Silveira, B.N. Ames, An alkyl hydroperoxide reductase induced by oxidative stress in Salmonella typhimurium and Escherichia coli: Genetic characterization and cloning of ahp, J. Bacteriol. 171 (1989) 2049-2055.

[34] P. Stragier, F. Richaud, F. Borne, J.C. Patte, Regulation of diaminopimelate decarboxylase synthesis in Escherichia coli: I. Identification of a lys $R$ gene encoding an activator of the lysA gene, J. Mol. Biol. 168 (1983) 307-320.

[35] S. Tabor, C.C. Richardson, A bacteriophage T7 RNA polymerase/ promoter system for controlled exclusive expression of specific genes, Proc. Natl. Acad. Sci. USA 82 (1985) 1074-1078.

[36] D. Touati, Cloning and mapping of the manganese superoxide dismutase gene (sodA) Escherichia coli K-12, J. Bacteriol. 155 (1983) 1078-1087.

[37] C.K. Tuggle, J.A. Fuchs, Glutathione reductase is not required for maintenance of reduced glutathione in Escherichia coli K-12, J. Bacteriol. 162 (1985) 448-450.

[38] E. Turlin, A. Danchin, F. Biville, Regulation of the early steps of 3-phenylpropionate catabolism in Escherichia coli, J. Mol. Biol. Microbiol. Biotechnol. 3 (2001) 127-133.

[39] J.E. Visick, S. Clarke, RpoS- and OxyR-independent induction of HPI catalase at stationary phase in Escherichia coli and identification of rpoS mutations in common laboratory strains, J. Bacteriol. 179 (1997) $4158-4163$.

[40] N.R. Waterfield, D.J. Bowen, J.D. Fetherston, R.D. Perry, R.H. Ffrench-Constant, The $t c$ genes of Photorhabdus: A growing family, Trends Microbiol. 9 (2001) 185-191.

[41] M. Zheng, X. Wang, L.J. Templeton, D.R. Smulski, R.A. LaRossa, G. Storz, DNA microarray-mediated transcriptional profiling of the Escherichia coli response to hydrogen peroxide, J. Bacteriol. 183 (2001) 4562-4570. 